\title{
Repeat propofol anesthesia does not exacerbate plaque deposition or synapse loss in APP/PS1 Alzheimer's disease mice
}

\author{
Adele Woodhouse 1* (D), Carmen Maria Fernandez-Martos ${ }^{1}$, Rachel Alice Kathryn Atkinson ${ }^{1}$, Kelsey Anne Hanson ${ }^{1}$, \\ Jessica Marie Collins' ${ }^{1}$, Aidan Ryan O'Mara', Nico Terblanche ${ }^{2,3,5}$, Marcus Welby Skinner ${ }^{4,5}$, \\ James Clement Vickers ${ }^{1}$ and Anna Elizabeth King ${ }^{1}$
}

\begin{abstract}
Background: There is increasing interest in whether anesthetic agents affect the risk or progression of Alzheimer's disease (AD). To mitigate many of the methodological issues encountered in human retrospective cohort studies we have used a transgenic model of AD to investigate the effect of propofol on AD pathology.

Methods: Six month-old amyloid precursor protein/presenilin 1 (APP/PS1) transgenic AD mice and control mice were exposed to 3 doses of propofol $(200 \mathrm{mg} / \mathrm{kg})$ or vehicle, delivered at monthly intervals.

Results: There was no difference in the extent of $\beta$-amyloid (A $\beta$ ) immunolabeled plaque deposition in APP/PS1 mice in vehicle versus propofol treatment groups. We also detected no difference in plaque-associated synapse loss in APP/PS1 mice following repeat propofol exposure relative to vehicle. Western blotting indicated that there was no difference in post-synaptic density protein 95 , synaptophysin or glutamic acid decarboxylase 65/67 expression in control or APP/PS1 mice subjected to repeat propofol treatment relative to vehicle.

Conclusions: These data suggest that repeat propofol anesthesia may not exacerbate plaque deposition or associated synapse loss in AD. Interestingly, this data also provides some of the first evidence suggesting that repeat propofol exposure in adult wild-type mice does not result in robust long-term alterations in the levels of key excitatory and inhibitory synaptic markers.
\end{abstract}

Keywords: Alzheimer's disease, $\beta$-amyloid plaques, Synapse, Synaptophysin, Glutamic acid decarboxylase

\section{Background}

Alzheimer's disease (AD) is the most common form of dementia and is forecast to become an increasing global burden with aging of the global populations [1]. AD is characterized by several pathological 'hallmarks' including $\beta$-amyloid (A $\beta$ ) plaques, neurofibrillary tangles, plaqueassociated dystrophic neurites and neuropil threads. The majority of AD cases are sporadic in nature [2] and are likely caused by a combination of genetic susceptibility and environmental factors that interact to precipitate disease onset. Exposure to anesthetics is one such environmental factor that may contribute to the development

\footnotetext{
* Correspondence: Adele.Woodhouse@utas.edu.au

${ }^{1}$ Wicking Dementia Research and Education Centre, University of Tasmania, Hobart, Australia

Full list of author information is available at the end of the article
}

and/or progression of $\mathrm{AD}$. There is increasing interest in the link between anesthetic exposure, post-operative cognitive dysfunction (POCD) and the onset and progression of AD [3-15]. Notably, best practice for the use of anesthetics in people with mild cognitive impairment (MCI) and $\mathrm{AD}$ is not yet defined $[3,16]$.

As life expectancy is increasing, there is a rise in the number of elderly people undergoing anesthesia [10], however, data regarding the effects of anesthesia on the onset and progression of $\mathrm{AD}$ are contentious. Retrospective studies have reported that previous exposure to anesthesia was significantly correlated with an increased risk of $\mathrm{AD}$ in people over 80 years of age [17] and that there was an inverse correlation between anesthetic exposure before 50 years of age and the age of onset of $\mathrm{AD}$ [18]. However, other retrospective and meta-analyses 
studies have shown no association between anesthetic exposure and $\mathrm{AD}[14,19,20]$. Moreover, there are substantial methodological issues to consider when interpreting the data from prospective randomized clinical trials; variations in perioperative/anesthetic procedures, impact of underlying conditions, lack of long-term follow up, poor controls, inadequate cognitive testing and surgery-associated inflammation [5, 10, 21].

POCD is a well-documented phenomena that shares mechanistic links with $\mathrm{AD}$. POCD is common following general anesthesia in the elderly $[7,22,23]$ and presents as memory loss, delirium, depression and impaired higher-level cognitive dysfunction [10]. POCD usually lasts only a few days, but POCD can persist for weeks and has been implicated in the development or progression of $\mathrm{AD}$ due to shared molecular mechanisms (increased CSF/brain $A \beta$ levels and tau phosphorylation) $[10,22,23]$. Although the extent of POCD following particular anesthetic agents and surgery types varies [24]; aging [25, 26], pre-existing cognitive impairment [26, 27] and harboring the $\varepsilon 4$ apolipoprotein allele $[26,28-30]$ all appear to play a role in the overall risk.

Propofol is a general anesthetic that is used for outpatient procedures (colonoscopy, endoscopy) through to extensive cardiac, hip and spinal surgeries. As older people often have several co-morbidities and/or chronic illness, they are commonly subjected to multiple surgical interventions. Propofol anesthesia has been reported to result in an increase [31-33], decrease [34, 35] and no change [36] in the incidence of POCD and dementia in humans. Likewise rodent studies have reported that exposure to propofol resulted in no change/decreased levels of $A \beta[11,37]$, and no change in plaque or tau pathology [38]. While behavioral studies following propofol anesthesia in rodents have observed no change [11, 38], decreased [39] or improved [13] cognitive function. However, when elderly patients were studied propofol use associated with POCD in approximately 50\% of cases, even following minor surgery [40, 41].

Propofol acts as a $\mathrm{GABA}_{\mathrm{A}}$ receptor agonist and a voltage-gated sodium channel antagonist [42-44] and it alters synapses in an age-dependent manner. In postnatal day 15 (P15) mice propofol exposure increased dendritic spine density in pyramidal neurons in the hippocampus (involved in memory formation and spatial navigation), the prefrontal cortex (involved in executive function, attention and memory) and the somatosensory cortex (which receives and processes sensory information from the body) $[45,46]$. In contrast, propofol exposure at P5 reduced dendritic spine density in the prefrontal cortex and this was shown to be long lasting (up to P90) [45]. No studies to date have examined the impact of propofol anesthesia on synaptic structures in adult or aged subjects, which is particularly relevant due to the synaptic dysfunction and progressive plaqueassociated synaptic loss that occurs in $\mathrm{AD}$ [47-49].

We investigated the impact of repeated propofol exposure on plaque deposition and synapses, in the APP/ PS1 transgenic AD mouse that develop $A \beta$ plaques and synaptic degeneration with aging. By using an $\mathrm{AD}$ mouse model we are able to mitigate many of the methodological issues encountered in retrospective cohort studies including variations in perioperative and anesthetic procedures, impact of underlying conditions and surgeryassociated inflammation.

\section{Methods \\ Mice}

All experiments were approved by the Animal Ethics Committee of the University of Tasmania and performed according to the Australian Code of Practice for the Care and Use of Animals for Scientific Purposes (ethics number A12324). All experiments used male $\mathrm{APP}_{\mathrm{SWE}} /$ PSENdE9 (APP/PS1; [50], APP/PS1xYFPH [51]); Jackson Laboratory, USA, Strain B6.Cg-Tg(Thy1-YFP ${ }^{+-}$) HJrs/J, Stock No. 003782), YFPH and $\mathrm{C} 57 \mathrm{Bl} / 6$ wild-type littermate mice at 6 months of age. APP/PS1 and APP/ PS1xYFPH mice over-express APP harboring familial AD mutations that result in increased expression of the APP cleavage product $A \beta$, and the development of $A \beta$ plaques and synaptic degeneration with aging [47, 50, 52]. Amyloid plaques and memory deficits appear at 6-7 months of age in APP/PS1 mice and are abundant by 9 months, however, APP/PS1 mice do not develop the neurofibrillary pathology characteristic of human AD [50]. These mice represent a dynamic model of $A \beta$ plaque and synaptic pathology that can be experimentally increased [53, 54] or decreased [55]. All animals were housed in standard conditions (12 h light/dark cycle, $20{ }^{\circ} \mathrm{C}$ ) with ad libitum access to food and water.

\section{Anesthetic exposure}

Six-month-old APP/PS1, APP/PS1xYFPH, YFPH and wild-type mice were randomly allocated to propofol or vehicle treatment groups; and administered propofol (200 mg/kg; Norbrook ${ }^{\circledR}$ Laboratories, Australia PTY Ltd) diluted in Intralipid ${ }^{\circ}$ (Fresenius Kabi Ltd., UKm 03380519) or a vehicle control (Intralipid ${ }^{\ominus}$, Fresenius Kabi Ltd., UKm 0338-0519) intraperitoneally (IP) three times at 6 (representing pathology onset time-point), 7 and 8 months of age. All animals were then terminally anesthetized and perfused at 9 months of age. The dose of propofol administered $(200 \mathrm{mg} / \mathrm{kg})$ results in the loss of the righting reflex in $>95 \%$ of adult mice [56]. During anesthetic exposure the mice breathed spontaneously and were kept warm on a heating pad until they 
recovered and were mobile. Information regarding anesthetic induction and emergence time (indicating by the presence of the righting reflex) were collected for each propofol exposure. Statistical analysis of the average emergence time was performed; a student's t-test (2 tailed, type 3; Microsoft Excel) with a $p$ value of 0.05 considered statistically significant. Data generated from APP/PS1 or wild-type mice were not significantly different from that of APP/PS1xYFPH or YFPH mice, respectively; thus these data were pooled and designated APP/ PS1 and control experimental groups.

\section{Immunohistochemistry and analysis}

Mice were terminally anesthetized (sodium pentobarbitone, $110 \mathrm{mg} / \mathrm{kg}, \mathrm{IP}$ ) and transcardially perfused (4\% paraformaldehyde in $0.01 \mathrm{M}$ phosphate buffered saline (PBS)). Brains were then cryoprotected (18\% and 30\% sucrose) and $40 \mu \mathrm{m}$ serial coronal sections were cut on a cryostat (Leica CM 1850). Immunohistochemistry for $\mathrm{A} \beta$ plaques (MOA $\beta-2$ antibody: 1:2000, Novus Biologicals, cat no. NBP2-13075) was performed as previously described [57]. Propofol and vehicle treated APP/PS1 positive mice ( $n=8$ and 6$)$ and APP/PS1 negative mice $(\mathrm{n}=8$ and 7) were used for plaque analysis. Immunolabeling for synaptic puncta (synaptophysin antibody: 1: 200, Millipore, cat no. AB9272, NIF Antibody Registry AB_570874) and staining with thioflavin-S (Sigma-Aldrich, cat no. T-1892) were performed as previously described $[53,57]$. Propofol and vehicle treated APP/PS1 mice $(n=3$ for both) were used for synaptic puncta analysis. Negative control experiments (omitting primary antibodies) eliminated all immunoreactivity. Primary antibodies were visualized with AlexaFluor goat anti-mouse/rabbit secondary antibodies (1:500, Molecular Probes).

Images of MOA $\beta 2$-labeling were captured on a Leica DM LB2 microscope (NIS-Elements D Imaging Software, Nikon Instruments) as previously described [57]. Images of synaptophysin immunolabeling and thioflavin$S$ staining were captured on a Perkin-Elmer Ultraview VOX spinning disk confocal imaging system (Volocity 6. 3 software, Perkin-Elmer) with the same laser power and exposure settings, as previously described [53]. All image collection and subsequent image analysis was performed by an investigator blinded to treatment group allocation. Analysis of $\mathrm{A} \beta$ plaques and thioflavin-S plaque-associated synapse loss were conducted with a custom unbiased image segmentation plugin for ImageJ based on a random-forests machine learning algorithm to segment images as plaques and synaptic puncta or background pixels [58]. The classifier was trained using a random selection of cropped images from the data set that were annotated with examples of plaques/synaptic puncta and background pixels to produce a forest of 50 trees with a maximum depth of 9 nodes. Each tree considered only a random bag of $5 \%$ of the training pixels, sampled with replacement. All analysis was conducted blinded to animal genotype/treatment group. Statistical analysis of the plaque density, average plaque size, plaque load, the density of and percentage area occupied by synaptophysinimmunoreactive synaptic puncta was performed using the student's t-test (2 tailed, type 3; Microsoft Excel) for analysis, with a $p$ value of 0.05 considered statistically significant. The $n$ required to power this study could not be predicted a priori as no previous study had investigated repeat propofol exposure in the APP/PS1 mouse model at 6 months of age with the same dosing regime as the current study, nor had any previous studies used the custom unbiased image segmentation plugin for ImageJ (based on a random-forests machine learning algorithm) to segment images as plaques and synaptic puncta or background pixels [58]. Therefore, for the maximum value of change detectable for each of our datasets refer to Additional file 1 . Data are presented as the mean \pm SEM. Figures were prepared in Adobe Photoshop and Adobe Illustrator, with brightness and contrast being enhanced for clarity consistently across images.

\section{Western blot}

Propofol and vehicle treated APP/PS1 ( $n=3$ and 2) and wild-type control mice ( $\mathrm{n}=3$ for both) were used for Western blot analysis. At 9 months of age, mice were terminally anesthetized (sodium pentobarbitone, $110 \mathrm{mg} /$ $\mathrm{kg}$ IP) and transcardially perfused (0.01 M PBS), the neocortex was then quickly removed and frozen in liquid nitrogen. Samples were homogenized in RIPA buffer (Sigma-Aldrich) containing a proteinase inhibitor cocktail (Roche) as previously [59]. Denatured proteins samples $(20 \mu \mathrm{g})$ were electrophoresed into Bolt ${ }^{\bullet}$ Bis-Tris Plus gels (Invitrogen), transferred to PVDF membranes (BioRad), and incubated overnight in primary antibody solution at $4{ }^{\circ} \mathrm{C}$. Primary antibodies used for Western blot were mouse anti-PSD-95 (1:1000; Abcam cat no. ab2723, NIF Antibody Registry AB_303248), rabbit anti-synaptophysin (1:1000; Millipore cat no. AB9272, NIF Antibody Registry AB_570874), mouse anti-GAD65 (1:1000; Abcam cat no. ab26113, NIF Antibody Registry AB_448989) and mouse anti-GAD67 (1:1000; Millipore cat no. MAB5406, NIF Antibody Registry AB_2278725). PSD-95 is a marker of the postsynaptic density of excitatory synapses, synaptophysin is a pre-synaptic marker of excitatory and inhibitory synapses, while GAD65 and GAD67 are markers of presynaptic inhibitory synapses. Membranes were washed and incubated with the corresponding anti-rabbit or antimouse horseradish peroxidase (HRP)-conjugated secondary antibody (1:7000; Dako) for $2 \mathrm{~h}$ at room temperature. Immunoreactive bands were visualized with enhanced chemiluminescence (ECL) solution using Luminata Forte 
Western horseradish peroxidase (HRP) substrate (Merck Millipore, Billerica, MA, USA). Membranes were then stripped and re-probed with a mouse anti-GAPDH (1: 1000, Millipore cat no. MAB374, NIF Antibody Registry AB_2107445), as a loading control. Western blot images were captured with the same exposure for all experimental groups for each protein of interest.

\section{Results}

No difference in emergence time from propofol anesthesia in APP/PS1 and control mice

To determine whether there was any difference in the response to propofol anesthesia the emergence time, indicated by the return of the righting reflex, was assessed for propofol treated control and APP/PS1 mice. There was no significant difference in the average emergence time from propofol anesthesia between $\mathrm{APP} / \mathrm{PS} 1(43.1 \pm 8.9 \mathrm{~min}, n=9)$ and control $(64.0 \pm 17$. 6 min, $n=7)$ mice $(p>0.05)$.

Repeat propofol exposure did not alter plaque deposition in the cortex of APP/PS1 mice

We assessed the impact of repeat propofol anesthesia on $A \beta$ plaque deposition in propofol and vehicle treated APP/PS1 mice. There was no significant difference in the $\mathrm{A} \beta$ plaque (MOA $\beta$-2-labeled) load between vehicle $(3.80 \pm 0.8 \%)$ and propofol $(3.85 \pm 1.0 \%)$ treated APP/PS1 mice compared to control mice $(\mathrm{p}>0.05$, Fig. 1 , Table 1$)$.
There was also no significant difference in the average size or density of $A \beta$ plaques between vehicle $(41.6 \pm 6$. $5 \mu \mathrm{m}^{2}, 0.030 \pm 0.007 / \mu \mathrm{m}^{2}$, respectively) or propofol (37.4 $\pm 6.6 \mu \mathrm{m}^{2}, 0.041 \pm 0.009 / \mu \mathrm{m}^{2}$, respectively) treated APP/ PS1 mice $(p>0.05$, Fig. 1 , Table 1$)$. No A $\beta$ plaques were observed in the vehicle or propofol treated control mice.

\section{Repeat propofol exposure did not alter plaque-associated} synaptic degeneration or the expression of synaptic proteins in APP/PS1 mice

As propofol increases GABAergic activity and decreases neuronal intrinsic excitability we assessed whether repeat propofol exposure altered the levels of excitatory and inhibitory synaptic markers in control and APP/PS1 mice as well as plaque-associated synaptic degeneration in APP/PS1 mice. Western blot analysis showed no robust difference in the expression levels of postsynaptic density protein 95 (PSD-95), synaptophysin and glutamic acid decarboxylase 65/67 (GAD65/67) in the cortex between vehicle and propofol treated control or APP/PS1 mice (Fig. 2). There was no difference in the density of, or percentage area occupied by, synaptophysinimmunoreactive synaptic puncta in the cortex $<40 \mu \mathrm{m}$ (region 1) from thioflavin-S plaques in vehicle $(0.359 \pm 0$. $017 / \mu^{2}, 1.55 \pm 0.12 \%$, respectively) or propofol (0.366 \pm $0.03 / \mu \mathrm{m}^{2}, 1.63 \pm 0.17 \%$, respectively) treated APP/PS1 mice $(p>0.05$; Table 1$)$. There was also no difference in the density of, or percentage area occupied by

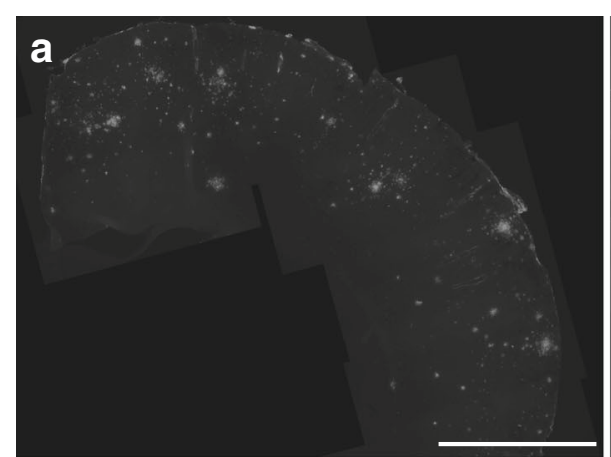

C

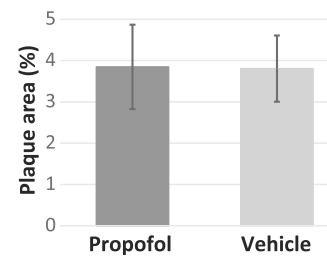

d

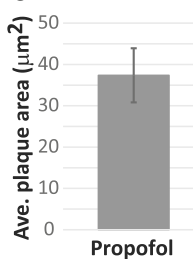

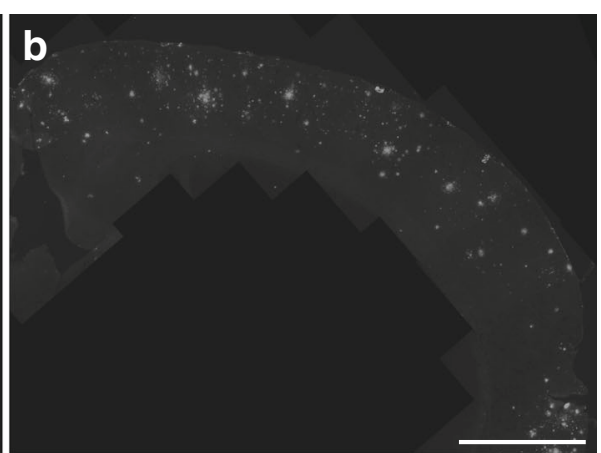

e
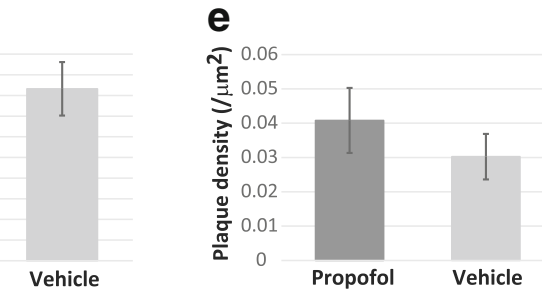

Fig. 1 No difference in A $\beta$ plaque load between propofol $(n=8)$ and vehicle $(n=6)$ treated APP/PS1 mice. a An example image of A $\beta$ plaque immunoreactivity in the cortex of an APP/PS1 mouse following repeated propofol exposure. $\mathbf{b}$ A representative image of $A \beta$ plaque immunolabeling the cortex of an APP/PS1 mouse following treatment with vehicle. $\mathbf{c}$ Bar graph showing the percentage of the cortex occupied by A $\beta$ plaques in propofol and vehicle treated APP/PS1 mice. $\mathbf{d}$ Bar graph showing the average size $\left(\mu \mathrm{m}^{2}\right)$ of A $\mathrm{A}$ plaques in the cortex of APP/ PS1 in the propofol and vehicle treatment groups. e Bar graph showing the average density of $A \beta$ plaques $\left(/ \mu m^{2}\right)$ in the cortex of propofol and vehicle exposed APP/PS1 mice. All data is shown as mean \pm SEM. Scale bar $=500 \mu \mathrm{m}$ 
a

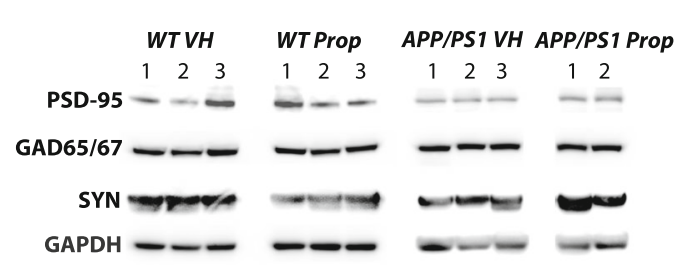

C

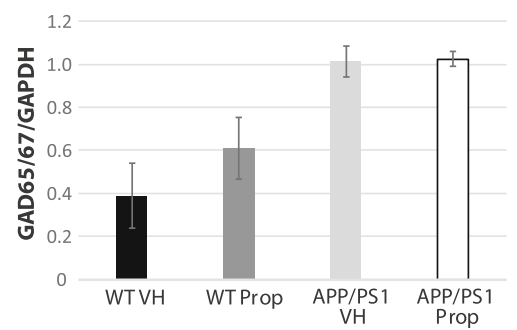

b

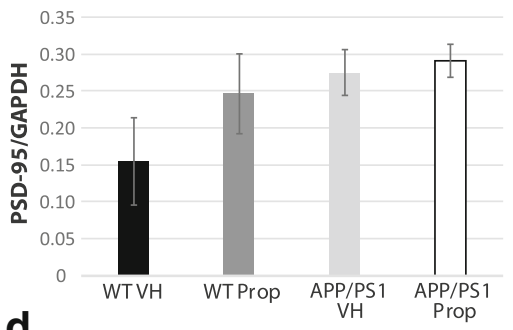

d

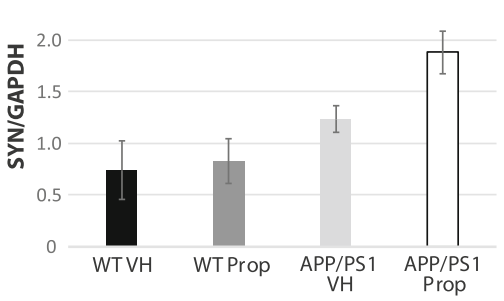

Fig. 2 No change in synaptic proteins between propofol and vehicle treated APP/PS1 ( $n=3$ and 2) and control wild-type ( $n=3$ for both) mice. Western blot analysis (a) showed no robust change in the expression levels of PSD-95, GAD65/67 and synaptophysin (SYN) in wild-type or APP/ PS1 mice treated multiple times with propofol (Prop) or vehicle (VH). Bar graphs show the mean intensity \pm SEM of PSD-95 (b), GAD65/67 (c) and synaptophysin (d) normalized to GAPDH

synaptophysin-immunoreactive synaptic puncta in the cortex between 40 and $80 \mu \mathrm{m}$ (region 2) away from thioflavin$\mathrm{S}$ plaques in vehicle $\left(0.268 \pm 0.060 / \mu \mathrm{m}^{2}, 2.57 \pm 0.63 \%\right.$, respectively) or propofol $\left(0.234 \pm 0.085 / \mu \mathrm{m}^{2}, 2.37 \pm 0.90 \%\right.$, respectively) treated APP/PS1 mice ( $p>0.05$; Table 1$)$.

\section{Discussion}

APP/PS1 and control mice were exposed to an average of $54 \mathrm{~min}$ of propofol anesthesia repeatedly at 6,7 and 8 months of age to determine the effect of repeat propofol anesthesia on $A \beta$ plaque pathology and synapses. We detected no difference in plaque load, plaque-associated synapse loss or the expression of excitatory and

Table 1 Mean values with standard error (SEM) for A $\beta$ plaque deposition and synaptophysin immunoreactivity data

\begin{tabular}{lll}
\hline & $\begin{array}{l}\text { APP/PS1 } \\
\text { Propofol }\end{array}$ & $\begin{array}{l}\text { APP/PS1 } \\
\text { Vehicle }\end{array}$ \\
\hline A $\beta$ plaque load & $3.85 \pm 1.0 \%$ & $3.80 \pm 0.8 \%$ \\
A $\beta$ plaque size & $37.4 \pm 6.6 \mu \mathrm{m}^{2}$ & $41.6 \pm 6.5 \mu^{2}$ \\
A 3 plaque density & $0.041 \pm 0.009 / \mu^{2}$ & $0.030 \pm 0.007 / \mu \mathrm{m}^{2}$ \\
Synapse density R1 & $0.366 \pm 0.03 / \mu \mathrm{m}^{2}$ & $0.359 \pm 0.017 / \mu \mathrm{m}^{2}$ \\
Synapse \% area R1 & $1.63 \pm 0.17 \%$ & $1.55 \pm 0.12 \%$, \\
Synapse density R2 & $0.234 \pm 0.085 / \mu \mathrm{m}^{2}$ & $0.268 \pm 0.060 / \mu \mathrm{m}^{2}$ \\
Synapse \% area R2 & $2.37 \pm 0.90 \%$ & $2.57 \pm 0.63 \%$ \\
\hline
\end{tabular}

$A \beta$ plaque load and $A \beta$ plaque density were determined using the MOA $\beta-2$ antibody in propofol $(n=8)$ and vehicle $(n=6)$ treated APP/PS1 mice Synapse density and percentage area were analyzed in vehicle $(n=3)$ and propofol $(n=3)$ treated APP/PS1 mice in: Region $1(\mathrm{R} 1),<40 \mu \mathrm{m}$ from Thioflavin-S plaques: and Region 2 (R2) $=40-80 \mu \mathrm{m}$ away from Thioflavine-S plaques inhibitory synaptic markers in APP/PS1 mice repeatedly anesthetized with propofol compared to APP/PS1 vehicle controls. We also provide some of the first evidence suggesting that repeat propofol exposure in adult wild-type mice does not result in robust long-term alterations in the levels of PSD-95, synaptophysin and GAD65/67.

Repeat propofol exposure did not result in a difference in A $\beta$ plaque load, plaque size or plaque density in APP/ PS1 mice in the current study. These data are in contrast to the decreased $A \beta$ load reported in 15-monthold $\operatorname{Tg} 2576 \mathrm{AD}$ mice and $\mathrm{A} \beta$ levels in 18-month-old wildtype mice following repeated propofol exposure [11, 37]. Differences in the AD mouse model used (Tg2576) [11], the age of the animals, the dose of propofol used $(26 \mathrm{mg} / \mathrm{kg}$ bolus and $2 \mathrm{mg} / \mathrm{kg} / \mathrm{min}$ infusion [11] $50 \mathrm{mg} / \mathrm{kg}$ bolus [37]), as well as the propofol dosing regime $[11,37]$ may account for the differing impact on $A \beta$ dynamics reported between this and previous studies. Our study focused on the impact of repeat propofol anesthesia between 6 and 9 months of age as $A \beta$ plaque deposition occurs at a rapid rate in APP/PS1 mice during this time [60]. It is possible that the impact of propofol exposure in older APP/ PS1 mice may differ. Indeed, Shao and colleagues (2014) observed improved performance in the Morris Water Maze in 22-month-old APP/PS1 and aged wild-type mice following weekly propofol exposure for 3 months [13]. In keeping with our data, behavioral studies have observed that repeated propofol exposure resulted in no difference in $\mathrm{Y}$ maze performance in 
Tg2576 AD mice [11]. Similarly, rat studies have reported that one propofol exposure did not significantly alter olfactory learning in aged rats [61], while repeat propofol exposure improved inhibitory avoidance performance [62]. Interestingly, a recent human prospective study did not detect a difference in cerebrospinal fluid levels of A $\beta 1-42$, total tau or phosphorylated tau between propofol exposed and control MCI groups [9]. Furthermore, at 2 year follow-up no difference in the rate of MCI progression or conversion to $\mathrm{AD}$ between propofol exposed (spinal surgery) MCI cases compared to non-surgery MCI controls was detected [9].

Notably, as APP/PS1 mice do not exhibit substantial tau pathology, it is possible that propofol may still influence the onset and/or progression of AD tau pathology. However, a recent study investigated the impact of $30 \mathrm{~min}$ of propofol exposure in $3 \times \operatorname{TgAD}$ mice, which develop both $A \beta$ and tau pathology indicates that this is not the case [38]. Mardini and colleagues detected no difference in performance between propofol exposed and control 3xTgAD mice in the Morris Water Maze both 3 weeks and 16 weeks following propofol exposure [38]. Likewise, at 18 weeks following propofol exposure there was no change in $A \beta$ plaque load, phosphorylatedtau aggregation or the number of activated microglia between the propofol exposed and control 3xTgAD mice [38]. This suggests that transient increases in tau hyperphosphorylation in wild-type and transgenic AD mice following a single propofol exposure [63, 64] does not result in long-lasting sequelae.

As propofol is a $\mathrm{GABA}_{\mathrm{A}}$ agonist we investigated the impact of repeat propofol anesthesia on the synaptic degeneration and dysfunction that occurs in AD [47-49]. There was no exacerbation of the plaque-associated synaptic loss in APP/PS1 mice treated with propofol versus vehicle, suggesting that repeat propofol exposure does not exacerbate synaptic degeneration. Furthermore, we provide some of the first data that indicates that repeat propofol anesthesia in adult mice does not have a robust long term effect on the levels of key excitatory and inhibitory synaptic proteins; PSD-95, synaptophysin and GAD65/67 were not altered between propofol and vehicle treated cohorts of APP/PS1 or control mice. This is pertinent as recent animal studies have suggested that the dysfunction of inhibitory neuron networks contribute to aberrant excitatory neuronal activity in $\mathrm{AD}[48,49]$, and decreased levels of $\mathrm{GABA}_{\mathrm{A}}$ receptor subunits have been also observed in human $\mathrm{AD}$ [65-69]. These data in adult mice are also in contrast to the long-lasting reduction in spine density in the prefrontal cortex observed following propofol exposure at P5 [45], as well as the propofol-induced increase in dendritic spine density in pyramidal neurons in the hippocampus and somatosensory cortex observed at P15 [46]. However, it should be noted that the design of these developmental studies $[45,46]$ differed from the current study in several ways including; the propofol dosing regime (40-50 $\mathrm{mg} / \mathrm{kg}$ propofol initial bolus with $1-1.5$ hourly injections of $20-25 \mathrm{mg} / \mathrm{kg}$ for a single $5-6 \mathrm{~h}$ propofol exposure), analysis of synapses (spine density analysis versus synaptic puncta analysis) and the brain region analyzed (prefrontal cortex, somatosensory cortex and hippocampus versus cingulate, motor and somatosensory cortex); which may account for differences in the synaptic data.

\section{Conclusions}

Our data, along with other studies investigating propofol exposure and $\mathrm{AD}$, suggest that propofol is unlikely to exacerbate plaque deposition or synapse alterations in $\mathrm{AD}$. However, as the APP/PS1 mouse model does not develop extensive tau pathology, it is important to note that propofol may still impact neural health and could mitigate the onset or progression of $\mathrm{AD}$. This study also provides some of the first data to demonstrate that key synaptic markers are not altered in adult wild-type mice following repeat propofol exposure.

\section{Additional file}

Additional file 1: The maximum change detectable for each dataset with $80 \%$ power (Graphpad Statmate 2). (DOCX $12 \mathrm{~kb}$ )

\section{Abbreviations \\ AD: Alzheimer's disease; APP: Amyloid precursor protein; A $\beta$ : $\beta$-amyloid; GABA: Gamma aminobutyric acid receptor A; GAD65: Glutamic acid decarboxylase isoform 65; GAD67: Glutamic acid decarboxylase isoform 67; GAPDH: Glyceraldehyde 3-phosphate dehydrogenase; IP: Intraperitoneally; MCl: Mild cognitive impairment; PBS: Phosphate buffered saline; POCD: Post- operative cognitive dysfunction; PS1: Presenilin 1; PSD-95: Post synaptic density protein 95; YFPH: Yellow fluorescent protein high}

\section{Funding}

This project was funded by the JO and JR Wicking Trust (Equity Trustees), National Health and Medical Research Foundation, the Dementia Australia Research Foundation (Postdoctoral Fellowships to A.W.) and the Royal Hobart Hospital Research Foundation. The funding bodies had no role in the design of the study and collection, analysis and interpretation of data and in writing the manuscript.

\section{Availability of data and materials}

The datasets used and/or analyzed during the current study are available from the corresponding author on reasonable request.

\section{Authors' contributions}

NT, MS, JV and AK designed research. AW, CF-M, RA, KH and AK performed research. AW, CF-M, RA, KH, JC, AO, and AK analyzed research. All authors contributed to manuscript preparation. All authors read and approved the final manuscript.

\section{Ethics approval}

The current study did not involve human participation, human data or human tissue.

All animal experiments were approved by the Animal Ethics Committee of the University of Tasmania and performed according to the Australian Code 
of Practice for the Care and Use of Animals for Scientific Purposes (ethics number A12324).

\section{Competing interests}

The authors declare that they have no competing interests.

\section{Publisher's Note}

Springer Nature remains neutral with regard to jurisdictional claims in published maps and institutional affiliations.

\section{Author details}

${ }^{1}$ Wicking Dementia Research and Education Centre , University of Tasmania Hobart, Australia. ${ }^{2}$ Tasmanian Health Service, Royal Hobart Hospital, Hobart, Australia. ${ }^{3}$ Menzies Institute for Medical Research, University of Tasmania, Hobart, Australia. ${ }^{4}$ Department of Health and Human Services Tasmania, Royal Hobart Hospital, Hobart, Australia. ${ }^{5}$ School of Medicine, University of Tasmania, Hobart, Australia.

\section{Received: 14 November 2017 Accepted: 13 April 2018}

\section{Published online: 25 April 2018}

\section{References}

1. Brookmeyer R, Johnson E, Ziegler-Graham K, Arrighi HM. Forecasting the global burden of Alzheimer's disease. Alzheimers Dement. 2007;3(3):186-91.

2. Campion D, Dumanchin C, Hannequin D, Dubois B, Belliard S, Puel M, Thomas-Anterion C, Michon A, Martin C, Charbonnier F, et al. Early-onset autosomal dominant Alzheimer disease: prevalence, genetic heterogeneity, and mutation spectrum. Am J Hum Genet. 1999;65(3):664-70.

3. Arora SS, Gooch JL, Garcia PS. Postoperative cognitive dysfunction, Alzheimer's disease, and anesthesia. Int J Neurosci. 2014;124(4):236-42.

4. Dong $Y$, Wu X, Xu Z, Zhang $Y, X i e ~ Z$. Anesthetic isoflurane increases phosphorylated tau levels mediated by caspase activation and Abeta generation. PLoS One. 2012;7(6):e39386.

5. Hudson AE, Hemmings $H C$ Jr. Are anaesthetics toxic to the brain? $\mathrm{Br}$ Anaesth. 2011;107(1):30-7.

6. Kapila AK, Watts HR, Wang T, Ma D. The impact of surgery and anesthesia on post-operative cognitive decline and Alzheimer's disease development: biomarkers and preventive strategies. J Alzheimers Dis. 2014;41(1):1-13.

7. Li HC, Chen YS, Chiu MJ, Fu MC, Huang GH, Chen CC. Delirium, Subsyndromal delirium, and cognitive changes in individuals undergoing elective coronary artery bypass graft surgery. J Cardiovasc Nurs. 2014;30(4): 340-5.

8. Liu H, Weng H. Up-regulation of Alzheimer's disease-associated proteins may cause enflurane anesthesia induced cognitive decline in aged rats. Neurol Sci. 2014;35(2):185-9.

9. Liu Y, Pan N, Ma Y, Zhang S, Guo W, Li H, Zhou J, Liu G, Gao M. Inhaled sevoflurane may promote progression of amnestic mild cognitive impairment: a prospective, randomized parallel-group study. Am J Med Sci. 2013;345(5):355-60.

10. Papon MA, Whittington RA, El-Khoury NB, Planel E. Alzheimer's disease and anesthesia. Front Neurosci. 2011;4:272.

11. Quiroga C, Chaparro RE, Karlnoski R, Erasso D, Gordon M, Morgan D, Bosco G, Rubini A, Parmagnani A, Paoli A, et al. Effects of repetitive exposure to anesthetics and analgesics in the Tg2576 mouse Alzheimer's model. Neurotox Res. 2014;26(4):414-21.

12. Reinsfelt B, Westerlind A, Blennow K, Zetterberg H, Ricksten SE. Open-heart surgery increases cerebrospinal fluid levels of Alzheimer-associated amyloid beta. Acta Anaesthesiol Scand. 2013;57(1):82-8.

13. Shao H, Zhang Y, Dong Y, Yu B, Xia W, Xie Z. Chronic treatment with anesthetic Propofol improves cognitive function and attenuates Caspase activation in both aged and Alzheimer's disease transgenic mice. J Alzheimers Dis. 2014;41(2):499-13.

14. Sprung J, Jankowski CJ, Roberts RO, Weingarten TN, Aguilar AL, Runkle KJ, Tucker AK, McLaren KC, Schroeder DR, Hanson AC, et al. Anesthesia and incident dementia: a population-based, nested, case-control study. Mayo Clin Proc. 2013:88(6):552-61.

15. Xie Z, McAuliffe S, Swain CA, Ward SA, Crosby CA, Zheng H, Sherman J, Dong $Y$, Zhang $Y$, Sunder $N$, et al. Cerebrospinal fluid abeta to tau ratio and postoperative cognitive change. Ann Surg. 2013;258(2):364-9.

16. Tang JX, Eckenhoff MF. Anesthetic effects in Alzheimer transgenic mouse models. Prog Neuro-Psychopharmacol Biol Psychiatry. 2013;47:167-71.
17. Bufill E, Bartes A, Moral A, Casadevall T, Codinachs M, Zapater E, Carles Rovira J, Roura P, Oliva R, Blesa R. Genetic and environmental factors that may influence in the senile form of Alzheimer's disease: nested case control studies. Neurologia. 2009:24(2):108-12.

18. Bohnen N, Warner MA, Kokmen E, Kurland LT. Early and midlife exposure to anesthesia and age of onset of Alzheimer's disease. Int J Neurosci. 1994; 77(3-4):181-5.

19. Gasparini M, Vanacore N, Schiaffini C, Brusa L, Panella M, Talarico G, Bruno G, Meco G, Lenzi GL. A case-control study on Alzheimer's disease and exposure to anesthesia. Neurol Sci. 2002;23(1):11-4.

20. Seitz DP, Shah PS, Herrmann N, Beyene J, Siddiqui N. Exposure to general anesthesia and risk of Alzheimer's disease: a systematic review and metaanalysis. BMC Geriatr. 2011;11:83.

21. Avidan MS, Evers AS. Review of clinical evidence for persistent cognitive decline or incident dementia attributable to surgery or general anesthesia. J Alzheimers Dis. 2011;24(2):201-16

22. Deo $H$, West $G$, Butcher $C$, Lewis $P$. The prevalence of cognitive dysfunction after conventional and computer-assisted total knee replacement. Knee. 2011:18(2):117-20.

23. Monk TG, Weldon BC, Garvan CW, Dede DE, van der Aa MT, Heilman KM, Gravenstein JS. Predictors of cognitive dysfunction after major noncardiac surgery. Anesthesiology. 2008;108(1):18-30.

24. Bilotta F, Qeva E, Matot I. Anesthesia and cognitive disorders: a systematic review of the clinical evidence. Expert Rev Neurother. 16(11):1311-320.

25. Evered LA, Silbert BS, Scott DA, Maruff P, Ames D, Choong PF. Preexisting cognitive impairment and mild cognitive impairment in subjects presenting for total hip joint replacement. Anesthesiology. 2011;114(6):1297-304.

26. Patel D, Lunn AD, Smith AD, Lehmann DJ, Dorrington KL. Cognitive decline in the elderly after surgery and anaesthesia: results from the Oxford project to investigate memory and ageing (OPTIMA) cohort. Anaesthesia. 2016;71(10):1144-52.

27. Silbert B, Evered L, Scott DA, McMahon S, Choong P, Ames D, Maruff P, Jamrozik K. Preexisting cognitive impairment is associated with postoperative cognitive dysfunction after hip joint replacement surgery. Anesthesiology. 2015;122(6):1224-34.

28. Cao L, Wang K, Gu T, Du B, Song J. Association between APOE epsilon 4 allele and postoperative cognitive dysfunction: a meta-analysis. Int J Neurosci. 2014;124(7):478-85.

29. Lelis RG, Krieger JE, Pereira AC, Schmidt AP, Carmona MJ, Oliveira SA, Auler JO Jr. Apolipoprotein E4 genotype increases the risk of postoperative cognitive dysfunction in patients undergoing coronary artery bypass graft surgery. J Cardiovasc Surg. 2006;47(4):451-6.

30. Schenning KJ, Murchison CF, Mattek NC, Silbert LC, Kaye JA, Quinn JF. Surgery is associated with ventricular enlargement as well as cognitive and functional decline. Alzheimers Dement. 2016:12(5):590-7.

31. Djaiani G, Silverton N, Fedorko L, Carroll J, Styra R, Rao V, Katznelson R. Dexmedetomidine versus Propofol sedation reduces delirium after cardiac surgery: a randomized controlled trial. Anesthesiology. 2016;124(2):362-8.

32. Royse CF, Andrews DT, Newman SN, Stygall J, Williams Z, Pang J, Royse AG. The influence of propofol or desflurane on postoperative cognitive dysfunction in patients undergoing coronary artery bypass surgery. Anaesthesia. 2011;66(6):455-64

33. Schoen J, Husemann L, Tiemeyer C, Lueloh A, Sedemund-Adib B, Berger KU, Hueppe M, Heringlake M. Cognitive function after sevoflurane- vs propofolbased anaesthesia for on-pump cardiac surgery: a randomized controlled trial. Br J Anaesth. 2011;106(6):840-50.

34. Qiao $Y$, Feng $H$, Zhao $T$, Yan $H$, Zhang $H$, Zhao X. Postoperative cognitive dysfunction after inhalational anesthesia in elderly patients undergoing major surgery: the influence of anesthetic technique, cerebral injury and systemic inflammation. BMC Anesthesiol. 2015;15:154.

35. Tang JX, Mardini F, Caltagarone BM, Garrity ST, Li RQ, Bianchi SL, Gomes O, Laferla FM, Eckenhoff RG, Eckenhoff MF. Anesthesia in presymptomatic Alzheimer's disease: a study using the triple-transgenic mouse model. Alzheimers Dement. 2011;7(5):521-31. e521

36. Egawa J, Inoue S, Nishiwada T, Tojo T, Kimura M, Kawaguchi T, Taniguchi S, Furuya $\mathrm{H}$, Kawaguchi $\mathrm{M}$. Effects of anesthetics on early postoperative cognitive outcome and intraoperative cerebral oxygen balance in patients undergoing lung surgery: a randomized clinical trial. Can J Anaesth. 2016;63(10):1161-9.

37. Zhang Y, Shao H, Dong Y, Swain CA, Yu B, Xia W, Xie Z. Chronic treatment with anesthetic propofol attenuates beta-amyloid protein levels in brain tissues of aged mice. Transl Neurodegener. 2014;3(1):8. 
38. Mardini F, Tang JX, Li JC, Arroliga MJ, Eckenhoff RG, Eckenhoff MF. Effects of propofol and surgery on neuropathology and cognition in the 3xTgAD Alzheimer transgenic mouse model. Br J Anaesth. 2017;119(3):472-80.

39. Pang $R$, Quartermain $D$, Rosman $E$, Turndorf $H$. Effect of propofol on memory in mice. Pharmacol Biochem Behav. 1993;44(1):145-51.

40. Hocker J, Stapelfeldt C, Leiendecker J, Meybohm P, Hanss R, Scholz J, Bein B. Postoperative neurocognitive dysfunction in elderly patients after xenon versus propofol anesthesia for major noncardiac surgery: a double-blinded randomized controlled pilot study. Anesthesiology. 2009;110(5):1068-76.

41. Rohan D, Buggy DJ, Crowley S, Ling FK, Gallagher H, Regan C, Moriarty DC Increased incidence of postoperative cognitive dysfunction $24 \mathrm{hr}$ after minor surgery in the elderly. Can J Anaesth. 2005;52(2):137-42.

42. Hales TG, Lambert JJ. The actions of propofol on inhibitory amino acid receptors of bovine adrenomedullary chromaffin cells and rodent central neurones. Br J Pharmacol. 1991;104(3):619-28.

43. Bai D, Pennefather PS, MacDonald JF, Orser BA. The general anesthetic propofol slows deactivation and desensitization of GABA(A) receptors. J Neurosci. 1999;19(24):10635-46.

44. Rehberg B, Duch DS. Suppression of central nervous system sodium channels by propofol. Anesthesiology. 1999;91(2):512-20.

45. Briner A, Nikonenko I, De Roo M, Dayer A, Muller D, Vutskits L. Developmental stage-dependent persistent impact of propofol anesthesia on dendritic spines in the rat medial prefrontal cortex. Anesthesiology. 2011;115(2):282-93.

46. De Roo M, Klauser P, Briner A, Nikonenko I, Mendez P, Dayer A, Kiss JZ, Muller D, Vutskits L. Anesthetics rapidly promote synaptogenesis during a critical period of brain development. PLoS One. 2009;4(9):e7043.

47. Mitew S, Kirkcaldie MT, Dickson TC, Vickers JC. Altered synapses and gliotransmission in Alzheimer's disease and AD model mice. Neurobiol Aging. 2013;34(10):2341-51.

48. Palop JJ, Chin J, Roberson ED, Wang J, Thwin MT, Bien-Ly N, Yoo J, Ho KO, Yu GQ, Kreitzer A, et al. Aberrant excitatory neuronal activity and compensatory remodeling of inhibitory hippocampal circuits in mouse models of Alzheimer's disease. Neuron. 2007:55(5):697-711.

49. Verret L, Mann EO, Hang GB, Barth AM, Cobos I, Ho K, Devidze N, Masliah E, Kreitzer AC, Mody I, et al. Inhibitory interneuron deficit links altered network activity and cognitive dysfunction in Alzheimer model. Cell. 2012;149(3):708-21.

50. Jankowsky JL, Fadale DJ, Anderson J, Xu GM, Gonzales V, Jenkins NA, Copeland NG, Lee MK, Younkin LH, Wagner SL, et al. Mutant presenilins specifically elevate the levels of the 42 residue beta-amyloid peptide in vivo: evidence for augmentation of a 42-specific gamma secretase. Hum Mol Genet. 2004;13(2):159-70.

51. Feng G, Mellor RH, Bernstein M, Keller-Peck C, Nguyen QT, Wallace M, Nerbonne JM, Lichtman JW, Sanes JR. Imaging neuronal subsets in transgenic mice expressing multiple spectral variants of GFP. Neuron. 2000;28(1):41-51.

52. Mitew S, Kirkcaldie MT, Dickson TC, Vickers JC. Neurites containing the neurofilament-triplet proteins are selectively vulnerable to cytoskeletal pathology in Alzheimer's disease and transgenic mouse models. Front Neuroanat. 2013;7:30.

53. Fernandez-Martos CM, King AE, Atkinson RA, Woodhouse A, Vickers JC. Neurofilament light gene deletion exacerbates amyloid, dystrophic neurite, and synaptic pathology in the APP/PS1 transgenic model of Alzheimer's disease. Neurobiol Aging. 2015;36(10):2757-67.

54. Stuart KE, King AE, Fernandez-Martos CM, Summers MJ, Vickers JC. Environmental novelty exacerbates stress hormones and Abeta pathology in an Alzheimer's model. Sci Rep. 2017;7(1):2764.

55. Stuart KE, King AE, Fernandez-Martos CM, Dittmann J, Summers MJ, Vickers JC. Mid-life environmental enrichment increases synaptic density in CA1 in a mouse model of Abeta-associated pathology and positively influences synaptic and cognitive health in healthy ageing. J Comp Neurol. 2017;525(8):1797-810.

56. Irifune M, Sugimura M, Takarada T, Maeoka K, Shimizu Y, Dohi T, Nishikawa T, Kawahara M. Propofol anaesthesia in mice is potentiated by muscimol and reversed by bicuculline. Br J Anaesth. 1999;83(4):665-7.

57. Collins JM, King AE, Woodhouse A, Kirkcaldie MT, Vickers JC. The effect of focal brain injury on beta-amyloid plaque deposition, inflammation and synapses in the APP/PS1 mouse model of Alzheimer's disease. Exp Neurol. 2015;267:219-29.

58. O'Mara A, King AE, Vickers JC, Kirkcaldie MTK: ImageSURF: An ImageJ plugin for batch pixel-based image segmentation using random forests. J Open Res Softw 2017, Accepted:doi /https://doi.org/10.5334//jors.5172
59. Liu Y, Atkinson RA, Fernandez-Martos CM, Kirkcaldie MT, Cui H, Vickers JC, King AE. Changes in TDP-43 expression in development, aging, and in the neurofilament light protein knockout mouse. Neurobiol Aging. 2015:36(2):1151-9.

60. Garcia-Alloza M, Robbins EM, Zhang-Nunes SX, Purcell SM, Betensky RA, Raju S, Prada C, Greenberg SM, Bacskai BJ, Frosch MP. Characterization of amyloid deposition in the APPswe/PS1dE9 mouse model of Alzheimer disease. Neurobiol Dis. 2006;24(3):516-24.

61. Erasso DM, Chaparro RE, Quiroga Del Rio CE, Karlnoski R, Camporesi EM, Saporta S. Quantitative assessment of new cell proliferation in the dentate gyrus and learning after isoflurane or propofol anesthesia in young and aged rats. Brain Res. 2012;1441:38-46.

62. Hauer D, Ratano P, Morena M, Scaccianoce S, Briegel I, Palmery M, Cuomo V, Roozendaal B, Schelling G, Campolongo P. Propofol enhances memory formation via an interaction with the endocannabinoid system. Anesthesiology. 2011;114(6):1380-8.

63. Chen $Y$, Run $X$, Liang Z, Zhao Y, Dai CL, labal K, Liu F, Gong CX. Intranasal insulin prevents anesthesia-induced hyperphosphorylation of tau in 3XTgAD mice. Front Aging Neurosci. 2014;6:100.

64. Whittington RA, Virag L, Marcouiller F, Papon MA, El Khoury NB, Julien C, Morin F, Emala CW, Planel E. Propofol directly increases tau phosphorylation. PLoS One. 2011;6(1):e16648.

65. Iwakiri M, Mizukami K, Ikonomovic MD, Ishikawa M, Hidaka S, Abrahamson EE, DeKosky ST, Asada T. Changes in hippocampal GABABR1 subunit expression in Alzheimer's patients: association with Braak staging. Acta Neuropathol. 2005;109(5):467-74

66. Limon A, Reyes-Ruiz JM, Miledi R. Loss of functional GABA(a) receptors in the Alzheimer diseased brain. Proc Natl Acad Sci U S A. 2012;109(25):10071-6.

67. Mizukami K, Ikonomovic MD, Grayson DR, Sheffield R, Armstrong DM. Immunohistochemical study of GABAA receptor alpha1 subunit in the hippocampal formation of aged brains with Alzheimer-related neuropathologic changes. Brain Res. 1998;799(1):148-55.

68. Rissman RA, De Blas AL, Armstrong DM. GABA(A) receptors in aging and Alzheimer's disease. J Neurochem. 2007;103(4):1285-92.

69. Rissman RA, Mishizen-Eberz AJ, Carter TL, Wolfe BB, De Blas AL, Miralles $C P$, Ikonomovic MD, Armstrong DM. Biochemical analysis of GABA(A) receptor subunits alpha 1, alpha 5, beta 1, beta 2 in the hippocampus of patients with Alzheimer's disease neuropathology. Neuroscience. 2003;120(3):695-704.

\section{Ready to submit your research? Choose BMC and benefit from:}

- fast, convenient online submission

- thorough peer review by experienced researchers in your field

- rapid publication on acceptance

- support for research data, including large and complex data types

- gold Open Access which fosters wider collaboration and increased citations

- maximum visibility for your research: over $100 \mathrm{M}$ website views per year

At BMC, research is always in progress.

Learn more biomedcentral.com/submissions 